\title{
KEPATUHAN ANTENATAL CARE DENGAN KEJADIAN PREEKLAMPSIA PADA IBU HAMIL DI PUSKESMAS KAYON KOTA PALANGKARAYA
}

\section{Antenatal Care Compliance With Preeklampsia In Public Health Center Of Kayon At Palangka Raya City}

\section{Fitria Ningsih ${ }^{\text {** }}$}

*IProgram Studi Sarjana

Kesehatan Masyarakat STIKES

Eka Harap, Palangka Raya,

Kalimantan Tengah

*email: feghanz@gmail.com

\begin{abstract}
Abstrak
Angka kematian ibu (AKI) merupakan salah satu indikator untuk melihat derajat kesehatan perempuan. Kematian perempuan usia subur disebabkan masalah terkait kehamilan, persalinan dan nifas salah satunya akibat dari preeklamsi

Tujuan penelitian ini adalah menganalisis hubungan antara kepatuhan antenatal care dengan kejadian preeklampsia pada ibu hamil di Puskesmas Kayon Kota Palangka Raya.

Desain penelitian ini adalah penelitian analitik dengan pendekatan retrospektif. Populasi penelitian ini adalah ibu hamil yang tercatat pada rekam medik tahun 2018 dan besar sampel penelitian ini sebanyak I 50 responden dengan tehnik sampling yang digunakan adalah consecutive sampling. Uji statistik yang digunakan pada penelitian ini adalah chi-square.

Hasil uji statistik dapat disimpulkan bahwa adanya hubungan antara kepatuhan antenal care dengan kejadian preklamsi dengan nilai $P$ Vallue 0,001 .

Oleh sebab itu, perlu dilakukan promosi kesehatan tentang pentingnya melaksanakan kunjungan antenatal care secara rutin yaitu agar tenaga kesehatan dapat melakukan deteksi dini adanya gejala preeklamsi pada ibu.
\end{abstract}

\begin{abstract}
Maternal mortality rate (MMR) is one indicator to look at the degree of women's health. Death of women of childbearing age is caused by problems related to pregnancy, childbirth and the puerperal, one of which is a result of preeclampsia.

The purpose of this study was to analyze the relationship between antenatal care adherence with the incidence of preeclampsia in pregnant women at the Kayon Health Center in Palangka Raya City.

The design of this study is analytical research with a retrospective approach. The study population was pregnant women recorded in the 2018 medical records and the sample size of this study were 150 respondents with a sampling technique used was consecutive sampling. The statistical test used in this study is chi-square.

The results of statistical tests can be concluded that there is a relationship between antenal care compliance with preeclampsia with a Vallue $P$ value of 0.001 .

Therefore, it is necessary to promote health about the importance of carrying out regular antenatal care visits so that health workers can make early detection of symptoms of preeclampsia in the mother.
\end{abstract}

\section{PENDAHULUAN}

Angka kematian ibu (AKI) merupakan indikator untuk melihat derajat kesehatan perempuan. Angka kematian ibu (AKI) di dunia masih terbilang tinggi, menurut data World Health Organization (WHO) pada tahun 20I3, ada sekitar 800 ibu di dunia meninggal setiap harinya akibat komplikasi kehamilan dan persalinan. Di Indonesia sendiri AKI masih terbilang tinggi bila di bandingkan dengan negara-negara tetangga Berdasarkan Survei Demografi dan Kesehatan Indonesia (SDKI) tahun 2012 angka kematian ibu mencapai 359 per 100.000 kelahiran hidup dan pada tahun 2015 mengalami penurunan sebesar 15\% yaitu 305 per 100.000 kelahiran hidup berdasarkan Survei Demografi dan Kesehatan Indonesia (SDKI) tahun 2012 angka kematian ibu mencapai 359 per 100.000 kelahiran hidup dan pada tahun 2015 mengalami penurunan sebesar $15 \%$ yaitu 305 per 
100.000 kelahiran hidup (Kementrian Kesehatan RI, $2017)$.

Berdasarkan data dari RSUD dr. Doris Sylvanus Palangka Raya menempati urutan kedua dari tahun 20I5. Dapat di lihat bahwa preeklampsia merupakan suatu kehamilan yang ditandai dengan sindrom multisistem yaitu penurunan perfusi organ sekunder hingga vasospasme dan aktivasi kaskade koagulasi. Kondisi ini menjadi komplikasi pada sekitar 3-6\% kehamilan dengan insiden I,5-2 kali lebih besar pada primigravida.

Preeklampsia adalah kejadian hipertensi yang terjadi setelah minggu ke-20 kehamilan dan disertai dengan proteinuria. Pada kehamilan preeklampsia terjadi invasi sel trofoblas hanya terjadi pada sebagian arteri spiralis di daerah miometrium sehingga terjadi gangguan fungsi plasenta maka plasenta tidak memenuhi kebutuhuan darah untuk nutrisi dan oksigen ke janin. Gangguan ini dapat menyebabkan pertumbuhan janin yang terhambat. Selain itu, preeklampsia juga merupakan faktor penting morbiditas dan mortalitas perinatal, karena berhubungan dengan kelahiran prematur dan pembatasan pertumbuhan dalam Rahim (Manuaba, 2012).

Salah satu faktor yang dapat menyebabkan terjadinya preeklampsia adalah riwayat Antenatal Care. Antenatal Care (ANC) adalah pemeriksaan kehamilan yang bertujuan untuk mengoptimalkan kesehatan mental dan fisik ibu hamil sehingga ibu mampu menghadapi persalinannya serta didapatkan ibu dan bayi yang sehat melalui standar pelayanan. Dengan melaksanakan kunjungan Antenatal Care secara teratur akan dapat mendeteksi secara dini adanya preeklamsia dalam kehamilan, mencegah terjadainya komplikasi pada preeklamsia serta dapat mempercepat rujukan sehingga dapat mengurangi morbiditas maupun mortalitas pada ibu hamil (Prawirohardjo, 20I2).

Oleh sebab itu upaya yang dapat dilakukan oleh tenaga kesehatan khususnya Bidan yaitu memotivasi ibu hamil untuk rutin dan teratur melakukan pemeriksaan kehamilan agar dapat terdeteksinya secara dini adanya gejala preeklamsia.

\section{METODOLOGI}

Desain penelitian pada penelitian ini adalah penelitian analitik dengan pendekatan retrospektif. Pada penelitian ini ingin mengetahui bagaimana hubungan kepatuhan ANC terhadap kejadian Preeklamsia. Populasi pada penelitian ini adalah ibu hamil yang tercatat di Puskesmas Kayon pada tahun 2018 dan besar sampel pada penelitian ini sebanyak 150 responden dengan menggunakan teknik consecutive sampling. Penelitian ini menggunakan data sekunder dari catatan rekam medik di Puskesmas Kayon. Peneliti melakukan pengambilan data di Rekam Medik untuk mendapatkan data tentang ibu hamil yang dengan preeklamsi maupun tidak preeklamsi dengan alat bantu check list yang telah disiapkan sesuai dengan variabel yang akan diukur. Uji statistik yang digunakan adalah uji Chi Square atau Kai Kuadrat. Tujuan dari digunakannya uji Chi Square adalah untuk menguji perbedaan proporsi/persentase antara beberapa kelompok data.

\section{HASIL DAN PEMBAHASAN}

\section{A. HASIL}

Tabel I. Distribusi Frekuensi Karateristik lbu Berdasarkan Umur dan Paritas, di Puskesmas Kayon Kota Palangka Raya Tahun 2018

\begin{tabular}{|l|c|c|}
\hline Karakteristik & F & $\%$ \\
\hline Umur & 9 & 6,0 \\
\hline$<20$ Tahun & 121 & 80,7 \\
\hline $20-35$ Tahun & 20 & 13,3 \\
\hline$>35$ Tahun & 59 & 39,3 \\
\hline Paritas & 39 & 26,0 \\
\hline Nullipara & 44 & 29,3 \\
\hline Primipara & 8 & 5,3 \\
\hline Multipara & 41 & 27,3 \\
\hline Grandemultipara & 109 & 72,7 \\
\hline Kejadian Preeklamasi & \multicolumn{2}{|}{} \\
\hline Ya & 77 & 51,3 \\
\hline Tidak
\end{tabular}




\begin{tabular}{|l|c|c|}
\hline Patuh & 73 & 48,7 \\
\hline Jumlah & 150 & 100 \\
\hline
\end{tabular}

Berdasarkan tabel di atas dapat diketahui bahwa ibu yang berada pada kelompok umur $<20$ tahun sebanyak 9 orang (6\%), umur 20-35 tahun sebanyak 121 orang $(80,7 \%)$ dan pada kelompok umur $>35$ tahun sebanyak 20 orang $(13,3 \%)$ dan paritas nullipara sebanyak 59 orang (39,3\%), primipara sebanyak 39 orang (26\%), multipara sebanyak 44 orang $(29,3 \%)$ dan gandemultipara sebanyak 8 orang (5,3\%).

Tabel 2. Hubungan Kepatuhan ANC dengan Kejadian Preeklamasia Di Puskesmas Kayon Kota Palangka Raya Tahun 2018

\begin{tabular}{|c|c|c|c|c|c|c|c|}
\hline \multirow[t]{2}{*}{$\begin{array}{l}\text { Kepatuhan } \\
\text { ANC }\end{array}$} & \multicolumn{2}{|c|}{ Preeklamasia } & \multicolumn{2}{|c|}{$\begin{array}{l}\text { Tidak } \\
\text { Preeklamasia }\end{array}$} & \multirow[t]{2}{*}{$\begin{array}{l}\mathrm{P} \\
\text { Value }\end{array}$} & \multirow[t]{2}{*}{ OR } & \multirow{2}{*}{$\begin{array}{l}95 \% \mathrm{CL} \\
\text { OR } \\
\text { Lowwer- } \\
\text { Upper }\end{array}$} \\
\hline & $\mathrm{n}$ & $\%$ & $n$ & $\%$ & & & \\
\hline $\begin{array}{l}\text { Tidak } \\
\text { Patuh }\end{array}$ & 30 & 39,3 & 47 & 61,0 & \multirow{3}{*}{0,001} & \multirow{3}{*}{3,598} & \multirow{3}{*}{$\begin{array}{l}1,636- \\
7,911\end{array}$} \\
\hline Patuh & II & 15,1 & 62 & 84,9 & & & \\
\hline Total & 41 & 27,3 & 109 & 72,7 & & & \\
\hline
\end{tabular}

Berdasarkan tabel di atas terlihat bahwa ibu hamil yang tidak patuh melakukan kunjungan ANC yang mengalami preeklamsi sebanyak 39\% sedangkan yang patuh melakukan kunjungan ANC yang mengalami preeklamsi sebanyak 15,1\%. Hasil uji statistik didapatkan $p$ value 0,001 , dengan $\mathrm{p}$ value $<0,05$ artinya ada hubungan yang signifikan antara kepatuhan ANC dengan kejadian preeklamsi. Hasil analisis diperoleh OR 3,5 artinya ibu hamil yang tidak patuh melakukan kunjungan ANC memiliki risiko 3,5 kali mengalami preeklamsia dibandingkan ibu yang patuh melakukan kunjungan ANC.

\section{B. PEMBAHASAN}

Berdasarkan hasil penelitian pada tabel I bahwa ibu yang berada pada kelompok umur $<20$ tahun sebanyak 9 orang (6\%), umur 20-35 tahun sebanyak I2I orang $(80,7 \%)$ dan pada kelompok umur > 35 tahun sebanyak 20 orang (13,3\%). Kehamilan bagi wanita dengan umur terlalu muda maupun umur terlalu tua merupakan suatu keadaan yang dapat menimbulkan risiko komplikasi kehamilan dan kematian ibu. Pada umur 20-35 tahun adalah periode yang aman untuk melahirkan dengan resiko kesakitan dan kematian ibu yang paling rendah (Sukesih, 2012). Pada hasil penelitian ini dari I 50 ibu diantaranya 41 orang $(27,3 \%)$ yang mengalami preeklamsia sedangkan 109 orang (72,7\%) tidak mengalami pre eklamsia. Dapat dilihat mayoritas kelompok umur ibu pada kelompok umur yang tidak berisiko yaitu 20-35 tahun yaitu sebanyak I2 I orang (80,7\%). Karena pada kelompok umur 20-35 tahun seorang wanita dianggap sistem reproduksinya sudah matang sehingga dapat mengurangi kejadian komplikasi pada masa kehamilan maupun persalinan.

Berdasarkan hasil penelitian pada tabel I bahwa ibu dengan paritas nullipara sebanyak 59 orang (39,3\%), primipara sebanyak 39 orang (26\%), multipara sebanyak 44 orang $(29,3 \%)$ dan gandemultipara sebanyak 8 orang (5,3\%). Berdasarkan hasil penelitian menunjukkan bahwa mayoritas ibu memiliki paritas yang berisiko terjadinya preeklamsi yaitu $<2$ anak dan $>3$ anak. Paritas merupakan jumlah anak yang dilahirkan oleh ibu baik dalam keadaan hidup maupun mati. Paritas seorang ibu tidak aman untuk hamil dan melahirkan adalah pada kehamilan pertama dan paritas tinggi (lebih dari 3), paritas 2-3 merupakan paritas paling aman ditinjau dari sudut kematian maternal (Saifuddin, 2010).

Berdasarkan hasil penelitian pada tabel 2 didapatkan ada hubungan yang signifikan antara kepatuhan ANC dengan kejadian preeklamsi ( $p=$ 0,00I dan OR 3,598 Cl 95\% (I,636-7,9II)). Antenatal Care (ANC) adalah pelayanan kesehatan yang diberikan oleh tenaga kesehatan untuk ibu selama kehamilan dan dilaksanakan sesuai dengan standar pelayanan kebidanan. Pelayanan ANC yang rutin mencakup minimal 4 kali kunjungan ditiap trimester (minimal I kali pada trimester I, I kali pada trimester II, dan 2 kali pada trimester III umur kehamilan) dilakukan pemeriksaan IOT berupa 
pemeriksaan fisik dan mental ibu hamil yakni tinggi badan dan timbang berat badan, ukur tekanan darah,nilai status gizi, pengukuran tinggi fundus uteri, menentukan presentasi dan denyut jantung janin, pemberian imunisasi TT, pemberian tablet zat besi (minimal 90 tablet) selama kehamilan, tes laboratorium (rutin dan khusus), tata laksana kasus dan temu wicara atau konseling (Kementrian Kesehatan RI, 2018). Tujuan dari pemeriksaan tersebut adalah mengetahui sekaligus mengontrol faktor risiko pada ibu hamil yang dapat mempersulit persalinan ibu nanti sehingga dapat dilakukan antisipasi sedini mungkin. Penilaian faktor risiko tersebut diantaranya risiko dari usia, jarak kehamilan, jumlah anak, tinggi badan minimum, riwayat keguguran, riwayat kehamilan sebelumnya, penyakit yang diderita, letak bayi serta yang paling berhubungan erat dengan preeklampsia adalah pemeriksaan pembengkakan yang ada pada muka/tungkai serta tekanan darah tinggi (Sudarti dan Afroh Fauziah, 2013). Menurut (Setyowati et al., 20I8) pelayanan antenatal yang diberikan sesuai dengan Standar Asuhan Kebidanan sangat mempengaruhi kondisi ibu dan janin, baik pada saat kehamilan, persalinan, maupun masa nifas (0-42 hari) dan neonates (0-28 hari). Faktor resiko juga dapat terdeteksi sehingga penanganan dan rujukan dapat dilakukan sedini mungkin. Sehingga dengan dilaksanakannya kunjungan ANC secara rutin akan dapat mengetahui faktor risiko ibu sedini mungkin serta mencegah terjadinya komplikasi dari preeklamsi.

Hal ini juga sejalan dengan penelitian Isnanda et al., (2014) di RSUD Ulin Banjarmasin bahwa antara pelayanan ANC dengan kejadian preeklampsia. Pelayanan ANC berpengaruh pada kejadian preeklampsia dapat terjadi karena masih belum maksimalnya pelayanan ANC yang diberikan kepada ibu hamil. Salah satu pemeriksaan ANC yang dianggap penting adalah penggunaan USG dalam pemeriksaan kehamilan karena berfungsi untuk mengetahui kondisi janin secara lebih tepat, sehingga akan mengurangi tingkat risiko pada ibu hamil.

Oleh sebab itu untuk meningkatkan kepatuhan masyarakat dalam melaksanakan kunjungan antenatal care maka perlu dilakukan promosi kesehatan tentang pentingnya melaksanakan kunjungan antenatal care secara rutin yaitu minimal kunjungan pada trimester I sebanyak I kali, trimester II sebanyak I kali dan trimester III sebanyak 2 kali. Agar dengan adanya kunjungan antenatal care secara rutin makan pihak tenaga kesehatan dapat melakukan penilaian atau dignosa sedini mungkin terkait dengan adanya gejala oreklamsi pada ibu sehingga dapat mengurangi risiko komplikasi pada kehamilan maupun persalinan pada ibu.

\section{KESIMPULAN}

I. Karaketristik ibu berdasarkan umur, mayoritas pada kelompok umur 20-35 tahun sebanyak I2I orang $(80,7 \%)$

2. Karaketristik ibu berdasarkan paritas, mayoritas memiliki pasritas nullipara sebanyak 59 orang (39,3\%), primipara sebanyak 39 orang (26\%), dan multipara sebanyak 44 orang $(29,3 \%)$

3. Hasil uji statistik didapatkan $p$ value 0,001 , dengan $P$ value $<0,05$ artinya ada hubungan yang signifikan antara kepatuhan ANC dengan kejadian preeklamsi. Hasil analisis diperoleh OR 3,5 artinya ibu hamil yang tidak patuh melakukan kunjungan ANC memiliki risiko 3,5 kali mengalami preeklamsia dibandingkan ibu yang patuh melakukan kunjungan ANC.

\section{UCAPAN TERIMA KASIH}

Berisi Informasi ucapan terima kasih serta penghargaan kepada pihak-pihak yang telah berpartisipasi dalam kegiatan penelitian yang dilakukan. Bisa kepada institusi penyedia anggaran maupun hibah (mencantumkan sumber dan skema hibah yang digunakan), pihak institusi tempat kegiatan penelitian dilakukan, narasumber, 
organisasi dan unsur masyarakat, serta sivitas akademika yang telah membantu pelaksanaan kegiatan penelitian.

\section{REFERENSI}

I. Kementrian Kesehatan RI. 2017. Kementerian Kesehatan Republik Indonesia. In Kementerian Kesehatan RI.

2. Manuaba. 2012. Ilmu Kebidanan, Penyakit Kandungan, dan KB. In Ilmu Kebidanan, Penyakit, Kandungan, dan KB. https://doi.org// 0.1055/s-2008$\underline{1043995}$

3. Prawirohardjo, S. 2012. Ilmu Kebidanan. Jakarta: Yayasan Bina Sarwono Prawirohardjo.

4. Sukesih, S. 2012. Universitas Indonesia Faktor Faktor Yang Berhubungan Dengan Perilaku Pemberian Asi Eksklusif Di Puskesmas Srondol Kota Semarang Tahun 2012 Skripsi Depok. Universitas Indonesia.

5. Kementrian Kesehatan RI. 2018. Profil Kesehatan Indonesia $2018 \quad$ Kemenkes RI. http://www.depkes.go.id/resources/download/pus datin/profil-kesehatan-indonesia/Data-danInformasi Profil-Kesehatan-Indonesia-2018.pdf

6. Sudarti dan Afroh Fauziah. 2013. Buku Ajar Asuhan Kebidanan Neonatus, Bayi, dan Anak Balita. Yogyakarta: Nuha Medika.

7. Setyowati, A., Ulya, N., \& Sa'adah, U. 2018. Faktorfaktor yang Mempengaruhi Pelaksanaan Pelayanan Antenatal Care Terpadu pada Bidan di Puskesmas Kota Pekalongan. Jurnal Kebidanan Harapan Ibu Pekalongan. https://doi.org/10.37402/jurbidhip.vol4.iss2.3

8. Isnanda, E. P., Noor, M. S., \& Musafaah. 2014. Hubungan Pelayanan Antenatal Care (Anc) Dengan Kejadian Preeklampsia Ibu Hamil Di Rsud Ulin Banjarmasin. Jurnal Publikasi Kesehatan Masyarakat. https://doi.org/I0.16285/j.rsm.2012.03.034

9. Saifuddin, A. 2010. Panduan Praktis Pelayanan Kesehatan Maternal dan Neonatal. Jakarta: Bina Pustaka. 